\title{
The association between obesity and race among Brazilian adults is dependent on sex and socio-economic status
}

\author{
Marina Campos Araujo ${ }^{1, *}$, Valéria Troncoso Baltar ${ }^{2}$, Edna Massae Yokoo ${ }^{2}$ and \\ Rosely Sichieri ${ }^{3}$ \\ ${ }^{1}$ Sergio Arouca National School of Public Health, Oswaldo Cruz Foundation/Ministry of Health, Rua Leopoldo \\ Bulhões 1480, sala 803, Bonsucesso, CEP 21041210, Rio de Janeiro, RJ, Brazil: ${ }^{2}$ Department of Epidemiology and \\ Biostatistics, Institute of Collective Health, Fluminense Federal University, Niterói, R, Brazil: ${ }^{3}$ Department of \\ Epidemiology, Social Medicine Institute, State University of Rio de Janeiro, Rio de Janeiro, RJ, Brazil
}

Submitted 7 July 2017: Final revision received 11 January 2018: Accepted 25 January 2018: First published online 4 March 2018

\begin{abstract}
Objective: To verify the association of race, independent of socio-economic status (SES), with obesity among Brazilian adults.

Design: We investigated data from the 2008-2009 Brazilian Household Budget Survey. Obesity was defined using the WHO classification. Self-declared race was classified as White, Black and 'Pardo' (Brown). Factor analysis with principal component extraction was used to derive the SES index. The association between race and obesity independent of SES, adjusted for demographic variables, was estimated using multiple logistic regression, accounting for the survey design. Interaction term between race and SES was tested.

Setting: Brazilian households ( $n$ 55970).

Subjects: Adults aged 20-65 years ( $n$ 80702).

Results: The prevalence of obesity was $14.9 \%$. The first factor explained $51 \%$ of the variance and was used as a SES indicator. Odds of obesity increased with increasing SES level for men and for Black women, whereas Brown and White women showed a decrease of obesity. The association between race and obesity was modified by SES level in both sexes. At lower level of SES ( $-2 \mathrm{SD})$, Black and Brown in comparison to White men had 35 and $27 \%$ decreased odds of obesity, respectively. For women, at lower SES level, only Black compared with White women had $30 \%$ decreased odds of obesity. At the higher SES level (+2 SD), Black women compared with White presented a threefold increase of obesity.

Conclusions: Racial disparities in obesity are SES level- and sex-dependent in Brazil. Strategies exclusively targeting reductions in SES disparities are likely ineffective for decreasing racial disparities in obesity among women.
\end{abstract}

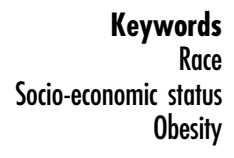

Obesity represents a major public health challenge worldwide $^{(1)}$, with a reduction of the obesity epidemic being the main target for the prevention and control of noncommunicable diseases by the $\mathrm{WHO}^{(2)}$. Therefore, detecting populations at high risk for obesity is an important task, as is understanding the possible factors leading to the increased susceptibility of these populations.

In high-income countries, obesity affects all ages and both sexes ${ }^{(3)}$. In the USA, the highest prevalence is observed among Black and Hispanic women, who are also the most poor and least educated populations ${ }^{(4-6)}$. In Brazil, although obesity is more pronounced among women and wealthy people, in the last 40 years, the prevalence has increased more among men and low-income women ${ }^{(7,8)}$. Although several Brazilian studies have focused on the socio-economic disparities in obesity prevalence, little attention has been given to racial disparities. One possible explanation is because in Brazil, as well as in other countries, race is generally treated as a proxy of socio-economic status (SES) due to the wellknown association between race and SES.

Some studies have suggested that racial differences in weight status cannot be completely explained by SES, and the associations of both race and SES with obesity are sex-dependent ${ }^{(4,9-12)}$. One of the few Brazilian studies that investigated these interrelationships verified an excessive weight gain among Black and Brown women compared with Whites. However, this association was only partially explained by low lifetime SES, and no association between race and weight gain was observed among men ${ }^{(12)}$.

Under the hypothesis that there are some racial aspects related to obesity not explained by SES, in the present study 
we aimed to verify the association of race, independent of SES, with obesity among Brazilian adults. To our knowledge, the present study is the first to investigate the relationship between race and obesity independent of SES in a nationwide sample from a middle-income country.

\section{Methods}

\section{Population}

The present study analysed data obtained from the 20082009 Household Budget Survey (HBS) conducted by the Brazilian Institute of Geography and Statistics. The Brazilian HBS sample was selected using a two-stage cluster sampling design. In the first stage, census tracts, the primary sampling units, were selected by systematic sampling with a probability proportional to the number of households. The census tracts were stratified to include representatives of all Brazilian regions, including both urban and rural areas, as well as different socio-economic levels. In the second stage, households were selected by simple random sampling. The 2008-2009 HBS included 4694 census tracts with 68373 households. Interviews were conducted for 55970 households and 190159 individuals of all ages and both sexes were investigated. In the present study, we included individuals aged 20-65 years living in urban areas, with the exception of pregnant women ( $n$ 1052) and a total of $2 \%$ of missing data ( $n$ 1651), yielding a final sample of 80702 Brazilian adults ${ }^{(13)}$.

The 2008-2009 HBS data are secondary data and are available for public online access. The Brazilian Institute of Geography and Statistics follows the Brazilian Government law (number 73177 of 20 November 1973) by respecting the ethical aspects of the individuals; the database information is confidential, with no subject identification, address or telephone number available.

\section{Data collection}

Body weight was measured using a portable electronic scale with a capacity of $150 \mathrm{~kg}$ and graduations of $100 \mathrm{~g}$. Height was assessed using a portable stadiometer. BMI was calculated as [weight $(\mathrm{kg})] /[\text { height }(\mathrm{m})]^{2}$ and obesity was defined according to the WHO BMI classification as BMI $\geq 30 \mathrm{~kg} / \mathrm{m}^{2(14)}$.

Racial classification was based on self-reported skin colour and was divided into five categories: White, Black, 'Pardo', Asian and Indigenous. In Brazil, 'Pardo' indicates an admixture of races, mainly White and Black. In our analysis, we hereafter use the word Brown to refer to 'Pardo' individuals. Since Asian and Indigenous people represented less than $1.2 \%$ of the included Brazilian adults, we excluded them from the present analysis.

SES characteristics were recorded during the household interviews and included one question related to education, one about income and three questions about perception of the family's living conditions. Education was estimated as the number of full years of study. Income was estimated as monthly household income, including all monetary and non-monetary sources of income (including gifts, donations). The total household income was divided by the number of members in the household to calculate the per capita income, which was classified into eight categories: $<1 / 4,1 / 4-1 / 2,1 / 2-1,1-2,2-5$ and $>5$ times the Brazilian minimum wage. The official minimum monthly wage in Brazil during the study time was \$US 174.40 (conversion rate at that time: 1 US dollar $=2.38$ Brazilian Real). The family's living conditions was based on one question related to the perception of how their monthly total income allows covering the needs of the family, divided into six categories: 'great difficulty', 'difficulty', 'some difficulty', 'slightly easy', 'easy' and 'very easy'. The other two questions were related to the sufficiency of foods and the quality of the foods afforded by the family. Both these questions were categorized into three options: 'rarely', 'sometimes' and 'always'. Trained interviewers were responsible for entering the data obtained during the household survey into a computer database.

\section{Data analyses}

Factor analysis with principal component extraction was used to derive a SES index using the five variables. The Kaiser-Meyer-Olkin test $(>0.6)$ and Bartlett's test of sphericity $(\leq 0.05)$ were used to determine whether correlations among the variables were sufficiently strong for factor analysis. Orthogonal Varimax rotation was used to simplify the interpretation of the factors. The factor explaining most of the variance was used as the SES index.

The association between obesity (dependent variable) and race (main explanatory variable) was estimated using multiple logistic regression stratified by sex. Model 1 evaluated the association adjusted for age (as a continuous variable) and region (North, Northeast, Midwest, South and Southeast Brazil). Model 2 considered Model 1 adjusted by the SES factor (estimated as a continuous variable by individual factor scores) and the interaction term of race and SES factor. OR of obesity were estimated for each sex, taking account of the contrasts between the races and interaction terms. In addition, OR were estimated for each sex and race considering the SES-level effects.

All statistical analyses were weighted and performed using the statistical software package SAS version 9.3, taking the sample design effect into account. Weighting factors were used to correct for non-responses, thus allowing population estimates.

\section{Results}

The study population comprised $51.4 \%$ Whites, $8.6 \%$ Blacks and $40.0 \%$ Brown individuals. Similar racial proportions were observed when analysed according to sex. 
The overall prevalence of obesity was $14.9 \%$ (males, $13.1 \%$; females, $16 \cdot 5 \%$ ). The prevalence rates of obesity among Blacks, Whites and Browns were 16.4, 15.1 and $14.2 \%$, respectively. The highest prevalence of obesity was found among Black women (20.6\%).

Important socio-economic disparities were observed when analysed according to race. For both sexes, Whites had greater education (years of school), greater income and better family perception of quality of life (measured by two proxy variables: whether the household quantity of food is sufficient and whether they consumed the kinds of foods they wanted) compared with Blacks and Browns. While $16 \%$ of White men received more than five times the minimum wage, only about $5 \%$ of Black and Brown men belonged to this income category. In addition, $74.4 \%$ of White men reported that the household quantity of food was always sufficient, compared with 55.2 and $56.8 \%$ of Black and Brown men, respectively. In contrast, $17 \cdot 8 \%$ of Black and $15 \cdot 2 \%$ of Brown men reported that they rarely consumed the kinds of foods they wanted, compared with $8.7 \%$ of White men. Similar results were observed among women (Table 1).

In the SES factor analysis, both the Kaiser-Meyer-Olkin index $(0.79)$ and Bartlett's test $(P<0 \cdot 01)$ indicated that the correlations among the five variables were sufficiently strong for factor analysis. The eigenvalue criterion (2.5) allowed for the identification of one factor of SES ( $51 \%$ of the explained variance). The factor loadings and commonalities were the greatest for income (Table 2).

As seen in Table 3, Model 1, the OR of obesity among Brown men was significantly lower than among White men, while there were no significant differences between Black and White men or between Brown and Black men. In contrast, Black and Brown women had 49 and $17 \%$ increased odds of obesity compared with White women, respectively. In Model 2, adjusted for socio-economic factors (individual factor scores), the interaction between race and SES factor was statistically significant $(P<0 \cdot 02)$. The association between obesity and race was different according to SES factor level in both sexes. At lower SES level (-2 SD), Black and Brown men had 35 and $27 \%$ decreased odds of obesity compared with White men, respectively. No significant associations for other SES levels or for Brown $v$. Black were observed. In addition, Black women compared with White women had 30\% decreased odds of obesity at lower SES level $(-2 \mathrm{SD})$ and a threefold increased odds at higher SES level (+2 SD), whereas Brown women had 35\% increased and $59 \%$ decreased odds of obesity compared with Black at lower (-2 SD) and higher SES level (+2 SD), respectively. There were no significant differences between Brown and White women in any SES level (Table 3).

For men, the odds of obesity increased with increasing SES. White, Black and Brown men presented OR of obesity of $1 \cdot 12,1.37$ and 1.26 per 1 SD increase in the SES factor, respectively. However, among women, only Blacks showed increased odds of obesity with increasing SES factor, whereas White and Brown women conversely showed decreases of 19 and 13\%, respectively (Table 4).

\section{Discussion}

The Brazilian adult population comprises an important admixture of Blacks and Whites; however, the socioeconomic disparities between races are great. In the present study, although the socio-economic disparities by racial category were similar between the sexes, the results related to the prevalence of obesity were not. Especially, among women, Blacks had the highest prevalence of obesity, while among men, Whites did. The association between obesity and race was clearly modified according to SES, mainly among women. Compared with White women, Black women had threefold increased odds of obesity at higher SES level and decreased odds of obesity at lower SES level. Moreover, the odds of obesity increased with increasing SES factor level in all racial categories among men, especially among Black men.

The positive relationship between income and obesity among men but not among women has already been documented in national Brazilian data ${ }^{(15)}$ and in a large Brazilian cohort $^{(16)}$. In developing countries, obesity has historically been a problem for wealthy people ${ }^{(17)}$. However, some studies have shown that obesity is becoming increasingly frequent among the poor, particularly among women ${ }^{(8,18,19)}$. Our study showed an important interaction of this association with SES, with Black women showing $17 \%$ increased odds of obesity with each increase of the SES factor, while for White and Brown women, the odds conversely decreased.

Some authors have suggested that the racial disparities in obesity independent of SES could be explained by physiological, psychological, cultural and environmental effects. Stress due to racial discrimination can have harmful health consequences, including negative mental outcomes $^{(20,21)}$, and may contribute to excessive BMI and body fat ${ }^{(22)}$. Such a physiological pathway could be explained by hormonal changes produced by stressors, which would activate the hypothalamic-pituitary-adrenal axis, resulting in imbalanced levels of insulin, cortisol and other glucocorticoids, which increase fat retention and may stimulate appetite and suppress the satiety system $^{(23-26)}$. Overeating related to psychological distress also increases the risk of weight gain over time ${ }^{(27,28)}$. Furthermore, some authors have verified positive associations of racism with BMI, waist circumference and measures of metabolic risk among Black women, suggesting that the effects of psychosocial stress on metabolic risk may be more pronounced in women than in men ${ }^{(29-31)}$.

In addition, cultural differences such as greater body size satisfaction among Black women compared with Whites ${ }^{(32)}$ and a preference for larger body sizes may also explain the racial disparities ${ }^{(33,34)}$. Greater consumption of 
Table 1 Prevalence of obesity according to demographic, socio-economic and food access characteristics among Brazilian adults from urban areas ( $n$ 80 702): $2008-2009$ Brazilian Household Budget Survey

\begin{tabular}{|c|c|c|c|c|c|c|c|c|c|c|c|c|}
\hline \multirow[b]{3}{*}{ Characteristic } & \multicolumn{6}{|c|}{ Men $(n 38391)$} & \multicolumn{6}{|c|}{ Women (n 42311) } \\
\hline & \multicolumn{2}{|c|}{$\begin{array}{c}\text { White } \\
(n 15677)\end{array}$} & \multicolumn{2}{|c|}{$\begin{array}{c}\text { Black } \\
(n 3510) \\
\end{array}$} & \multicolumn{2}{|c|}{$\begin{array}{c}\text { Brown } \\
(n \text { 19204) }\end{array}$} & \multicolumn{2}{|c|}{$\begin{array}{c}\text { White } \\
(n 18147)\end{array}$} & \multicolumn{2}{|c|}{$\begin{array}{c}\text { Black } \\
(n 3475)\end{array}$} & \multicolumn{2}{|c|}{$\begin{array}{l}\text { Brown } \\
(n 20689)\end{array}$} \\
\hline & $\begin{array}{l}\% \text { or } \\
\text { Mean }\end{array}$ & $95 \% \mathrm{Cl}$ & $\begin{array}{l}\% \text { or } \\
\text { Mean }\end{array}$ & $95 \% \mathrm{Cl}$ & $\begin{array}{l}\% \text { or } \\
\text { Mean }\end{array}$ & $95 \% \mathrm{Cl}$ & $\begin{array}{l}\% \text { or } \\
\text { Mean }\end{array}$ & $95 \% \mathrm{Cl}$ & $\begin{array}{l}\% \text { or } \\
\text { Mean }\end{array}$ & $95 \% \mathrm{Cl}$ & $\begin{array}{l}\% \text { or } \\
\text { Mean }\end{array}$ & $95 \% \mathrm{Cl}$ \\
\hline Prevalence of obesity $\left(\mathrm{BMI} \geq 30 \mathrm{~kg} / \mathrm{m}^{2}\right)(\%)$ & $14 \cdot 3$ & $13 \cdot 4,15 \cdot 2$ & $12 \cdot 0$ & $10 \cdot 4,13 \cdot 7$ & $11 \cdot 8$ & $11 \cdot 1,12 \cdot 5$ & $15 \cdot 9$ & $15 \cdot 1,16 \cdot 8$ & $20 \cdot 6$ & $18 \cdot 5,22 \cdot 7$ & $16 \cdot 5$ & $15 \cdot 7,17 \cdot 3$ \\
\hline Age (mean of years) & 39.2 & $38.9,39.5$ & 38.1 & $37.5,38 \cdot 7$ & 37.6 & $37.3,37.9$ & 40.0 & $39.8,40.3$ & 39.5 & $38.9,40 \cdot 1$ & 38.6 & $38.4,38.9$ \\
\hline Education (mean of full years of study) & $9 \cdot 2$ & $9 \cdot 0,9 \cdot 3$ & $7 \cdot 2$ & $7 \cdot 0,7 \cdot 4$ & 7.4 & $7 \cdot 3,7.5$ & $9 \cdot 3$ & $9 \cdot 2,9 \cdot 4$ & $7 \cdot 4$ & $7 \cdot 2,7 \cdot 6$ & $7 \cdot 6$ & $7 \cdot 5,7 \cdot 7$ \\
\hline \multicolumn{13}{|l|}{$\begin{array}{l}\text { Monthly household per capita income (Brazilian } \\
\text { minimum wage equivalents) (\%) }\end{array}$} \\
\hline$<1 / 4$ & 1.4 & $1 \cdot 1,1 \cdot 6$ & 4.4 & $3.4,5.4$ & 4.4 & $4.0,4.9$ & 1.6 & $1.3,1.9$ & 4.9 & $3 \cdot 9,6 \cdot 0$ & 4.7 & $4 \cdot 3,5 \cdot 1$ \\
\hline $1 / 4-1 / 2$ & $5 \cdot 1$ & $4 \cdot 6,5 \cdot 6$ & $12 \cdot 8$ & $11 \cdot 2,14.5$ & 13.7 & $12 \cdot 8,14.5$ & 5.4 & $5.0,5.9$ & 13.9 & $12 \cdot 1,15 \cdot 8$ & 14.5 & $13 \cdot 6,15 \cdot 3$ \\
\hline $1 / 2-1$ & $16 \cdot 5$ & $15 \cdot 4,17 \cdot 6$ & $27 \cdot 3$ & $25 \cdot 0,29 \cdot 6$ & $27 \cdot 4$ & $26 \cdot 3,28 \cdot 5$ & $17 \cdot 2$ & $16 \cdot 2,18 \cdot 2$ & $31 \cdot 7$ & $29 \cdot 1,34 \cdot 3$ & 27.9 & $26 \cdot 9,29 \cdot 1$ \\
\hline $1-2$ & $28 \cdot 7$ & $27 \cdot 3,30 \cdot 1$ & 31.5 & $28 \cdot 8,34 \cdot 2$ & 29.2 & $28 \cdot 1,30 \cdot 4$ & 29.2 & $28 \cdot 0,30 \cdot 4$ & $27 \cdot 6$ & $25 \cdot 2,30 \cdot 1$ & $28 \cdot 7$ & $27 \cdot 5,29.9$ \\
\hline $2-5$ & $32 \cdot 2$ & $30 \cdot 7,33 \cdot 7$ & $18 \cdot 7$ & $16 \cdot 5,20 \cdot 9$ & 19.9 & $18 \cdot 7,21 \cdot 1$ & 30.9 & $29 \cdot 5,32 \cdot 2$ & $16 \cdot 6$ & $14 \cdot 4,18 \cdot 2$ & $19 \cdot 3$ & $18 \cdot 2,20 \cdot 5$ \\
\hline$>5$ & $16 \cdot 1$ & $14 \cdot 8,17 \cdot 5$ & $5 \cdot 3$ & $3 \cdot 3,7 \cdot 2$ & $5 \cdot 3$ & $4 \cdot 6,6 \cdot 0$ & $15 \cdot 7$ & $14 \cdot 4,17 \cdot 0$ & $5 \cdot 2$ & $3.7,6 \cdot 8$ & 4.8 & $4 \cdot 2,5 \cdot 5$ \\
\hline \multicolumn{13}{|c|}{$\begin{array}{l}\text { Family perception of whether their total income allows } \\
\text { covering the needs of the family each month (\%) }\end{array}$} \\
\hline Great difficulty & 11.4 & $10 \cdot 5,12 \cdot 3$ & 23.7 & $21 \cdot 4,26 \cdot 1$ & 21.2 & $20 \cdot 1,22 \cdot 3$ & $12 \cdot 9$ & $12 \cdot 0,13 \cdot 7$ & $27 \cdot 2$ & $24.7,29 \cdot 7$ & 21.5 & $20 \cdot 5,22 \cdot 6$ \\
\hline Difficulty & $18 \cdot 3$ & $17 \cdot 1,19 \cdot 4$ & $24 \cdot 0$ & $21 \cdot 6,26 \cdot 4$ & $23 \cdot 1$ & $22 \cdot 0,24 \cdot 1$ & $19 \cdot 2$ & $18 \cdot 2,20 \cdot 3$ & $24 \cdot 6$ & $22 \cdot 0,27 \cdot 2$ & $23 \cdot 3$ & $22 \cdot 3,24 \cdot 3$ \\
\hline Some difficulty & 39.5 & $38.1,41.0$ & 35.8 & $33 \cdot 0,38.5$ & $35 \cdot 3$ & $34 \cdot 0,36 \cdot 6$ & 37.9 & $36 \cdot 6,39 \cdot 3$ & 33.4 & $30.5,36 \cdot 3$ & 36.4 & $35 \cdot 2,37 \cdot 6$ \\
\hline Slightly easy & $17 \cdot 6$ & $16 \cdot 5,18 \cdot 7$ & $10 \cdot 6$ & $8 \cdot 9,12 \cdot 3$ & $12 \cdot 2$ & $11 \cdot 3,13 \cdot 1$ & $16 \cdot 9$ & $15 \cdot 8,18 \cdot 0$ & 9.9 & $8 \cdot 1,11.8$ & 11.8 & $11 \cdot 0,12.5$ \\
\hline Easy & $12 \cdot 0$ & $11 \cdot 0,13 \cdot 0$ & $5 \cdot 2$ & $4 \cdot 2,6 \cdot 2$ & 7.5 & $6 \cdot 8,8 \cdot 3$ & 11.9 & $11 \cdot 0,12 \cdot 9$ & 4.4 & $3 \cdot 4,5 \cdot 4$ & $6 \cdot 4$ & $5 \cdot 8,7 \cdot 0$ \\
\hline Very easy & $1 \cdot 2$ & $0.9,1 \cdot 6$ & 0.6 & $0.2,1 \cdot 0$ & 0.7 & $0.5,0.9$ & $1 \cdot 1$ & $0.8,1 \cdot 4$ & 0.5 & $0.3,0.7$ & 0.6 & $0.4,0.7$ \\
\hline \multicolumn{13}{|c|}{$\begin{array}{l}\text { Family perception whether the household quantity } \\
\text { of food is sufficient (\%) }\end{array}$} \\
\hline Rarely & $5 \cdot 8$ & $5 \cdot 1,6 \cdot 5$ & $11 \cdot 7$ & $10 \cdot 0,13 \cdot 5$ & $11 \cdot 6$ & $10 \cdot 7,12 \cdot 5$ & 5.9 & $5 \cdot 2,6 \cdot 4$ & $14 \cdot 7$ & $12 \cdot 4,17 \cdot 0$ & $11 \cdot 3$ & $10 \cdot 4,12 \cdot 2$ \\
\hline Sometimes & $19 \cdot 7$ & $18 \cdot 5,21 \cdot 0$ & $33 \cdot 1$ & $30 \cdot 3,35 \cdot 9$ & 31.6 & $30 \cdot 2,33 \cdot 0$ & 20.8 & $19 \cdot 6,22 \cdot 1$ & $32 \cdot 3$ & $29 \cdot 7,34.8$ & 31.9 & $30 \cdot 7,33 \cdot 1$ \\
\hline Always & $74 \cdot 4$ & $73.0,75 \cdot 9$ & $55 \cdot 2$ & $52 \cdot 1,58 \cdot 3$ & $56 \cdot 8$ & $55 \cdot 3,58 \cdot 4$ & $73 \cdot 3$ & $71.9,74 \cdot 8$ & $53 \cdot 0$ & $49 \cdot 9,56 \cdot 2$ & 56.8 & $55 \cdot 4,58 \cdot 1$ \\
\hline \multicolumn{13}{|c|}{$\begin{array}{l}\text { Family perception whether they consume the kinds } \\
\text { of foods they want (\%) }\end{array}$} \\
\hline Rarely & 8.7 & $7 \cdot 7,9 \cdot 7$ & $17 \cdot 8$ & $15 \cdot 6,20 \cdot 1$ & $15 \cdot 2$ & $14 \cdot 0,16 \cdot 3$ & 8.7 & $7 \cdot 9,9.5$ & $17 \cdot 2$ & $15 \cdot 1,19 \cdot 4$ & $15 \cdot 3$ & $14.3,16 \cdot 3$ \\
\hline Sometimes & 47.9 & $46 \cdot 3,49 \cdot 4$ & 57.8 & $54 \cdot 8,60 \cdot 8$ & 55.7 & $54 \cdot 2,57 \cdot 1$ & $49 \cdot 3$ & $47 \cdot 7,50 \cdot 8$ & $56 \cdot 4$ & $53 \cdot 2,59 \cdot 7$ & $56 \cdot 6$ & $55 \cdot 4,57 \cdot 9$ \\
\hline Always & 43.4 & $41 \cdot 8,45 \cdot 0$ & $24 \cdot 3$ & $21 \cdot 9,26 \cdot 8$ & 29.2 & $27 \cdot 8,30 \cdot 5$ & $42 \cdot 0$ & $40 \cdot 5,43 \cdot 5$ & $26 \cdot 3$ & $23 \cdot 6,29 \cdot 0$ & $28 \cdot 0$ & $26 \cdot 8,29 \cdot 2$ \\
\hline
\end{tabular}


fast foods ${ }^{(35)}$, higher rates of obesity in areas of high concentrations of Black people ${ }^{(36)}$ and also a lower rate of breast-feeding among racial minorities are additional

Table 2 Socio-economic factors, factor loads and communalities $\left(h^{2}\right)$ resulting from the factor analysis among Brazilian adults from urban areas ( $n$ 80702): 2008-2009 Brazilian Household Budget Survey)

\begin{tabular}{|c|c|c|}
\hline Socio-economic factor & $\begin{array}{l}\text { Factor } \\
\text { loading }\end{array}$ & $h^{2}$ \\
\hline Education & 0.61 & 0.38 \\
\hline \multicolumn{3}{|l|}{ Income (two proxy variables) } \\
\hline $\begin{array}{l}\text { Monthly household per capita income } \\
\text { (Brazilian minimum wage equivalents) }\end{array}$ & 0.76 & 0.57 \\
\hline $\begin{array}{l}\text { Family perception of how their total income } \\
\text { allows covering the needs of the family each } \\
\text { month }\end{array}$ & 0.76 & 0.57 \\
\hline \multicolumn{3}{|l|}{ Food access (two proxy variables) } \\
\hline $\begin{array}{l}\text { Family perception whether the household } \\
\text { quantity of food is sufficient }\end{array}$ & 0.71 & 0.51 \\
\hline $\begin{array}{l}\text { Family perception whether they consume the } \\
\text { kinds of foods they want }\end{array}$ & 0.73 & 0.54 \\
\hline Eigenvalue & 2.56 & \\
\hline$\%$ of accumulated explained variance & $51 \cdot 29$ & \\
\hline
\end{tabular}

aspects promoting obesogenic environments ${ }^{(37)}$. These findings suggesting physiological, psychological and cultural differences among Black and White Brazilian women indicate the need for more in-depth explorations of these pathways to obesity in Brazil. One limitation of our study was that we could not quantify the contribution of these factors in our analysis.

A limitation of the database was that the survey lacked information on some proximal factors determining obesity. Food intake information was available only for less than $20 \%$ of the total HBS sample and physical activity was not measured. In addition, the cross-sectional study design limited us not to evaluate changes of factors related to SES and development of obesity. On the other hand, the study conducted the analysis in a large national probabilistic sample with a great admixture of races and welldocumented and measured variables.

Few studies have explored the association of obesity and race by SES level in Brazil. Chor et al. ${ }^{(12)}$ showed that the excessive weight gain among Black and Brown Brazilian women compared with Whites could be only

Table 3 Multiple survey logistic regression analysis of the effect of race on obesity among Brazilian adults from urban areas ( $n$ 80 702): 2008-2009 Brazilian Household Budget Survey

\begin{tabular}{|c|c|c|c|c|c|c|}
\hline \multirow[b]{2}{*}{ Model } & \multicolumn{3}{|c|}{ Men ( $n$ 38391) } & \multicolumn{3}{|c|}{ Women ( $n$ 42311) } \\
\hline & $\mathrm{OR}^{*}$ & $95 \% \mathrm{Cl}$ & $P$ & $\mathrm{OR}^{*}$ & $95 \% \mathrm{Cl}$ & $P$ \\
\hline \multicolumn{7}{|c|}{ Model 1: race + age (years) + region } \\
\hline Black $v$. White & 0.89 & $0.75,1.06$ & 0.19 & 1.49 & $1.29,1.72$ & $<0.01$ \\
\hline Brown v. White & 0.88 & $0.80,0.98$ & 0.02 & 1.17 & $1.07,1.28$ & $<0.01$ \\
\hline Brown v. Black & 0.99 & $0.84,1.17$ & 0.94 & 0.78 & $0.68,0.90$ & $<0.01$ \\
\hline \multicolumn{7}{|c|}{ Model 2: Model $1+$ SES factor (individual factor scores) + interaction term race $\times$ SES factor $†$} \\
\hline \multicolumn{7}{|c|}{ Black $v$. White } \\
\hline-2 SD of SES factor $\ddagger$ & 0.65 & $0.44,0.96$ & 0.03 & 0.70 & $0.52,0.94$ & 0.02 \\
\hline $0 \mathrm{SD}$ of SES factor & 0.96 & $0.81,1.15$ & 0.69 & 1.45 & $1.25,1.68$ & $<0.01$ \\
\hline$+2 \mathrm{SD}$ of SES factor & 1.44 & $0.96,2.17$ & 0.08 & 3.00 & $2 \cdot 10,4 \cdot 30$ & $<0.01$ \\
\hline \multicolumn{7}{|l|}{ Brown $v$. White } \\
\hline-2 SD of SES factor & 0.73 & $0.58,0.92$ & 0.01 & 0.94 & $0 \cdot 76,1 \cdot 17$ & 0.59 \\
\hline 0 SD of SES factor & 0.93 & $0.83,1.03$ & 0.15 & 1.07 & $0.98,1.18$ & 0.13 \\
\hline+2 SD of SES factor & 1.18 & $0.96,1.44$ & 0.12 & 1.22 & $1.00,1.49$ & 0.05 \\
\hline \multicolumn{7}{|l|}{ Brown v. Black } \\
\hline-2 SD of SES factor & 1.13 & $0.77,1.64$ & 0.54 & 1.35 & $1.01,1.82$ & 0.04 \\
\hline 0 SD of SES factor & 0.96 & $0.81,1.14$ & 0.63 & 0.74 & $0.64,0.86$ & $<0.01$ \\
\hline$+2 \mathrm{SD}$ of SES factor & 0.82 & $0.54,1.24$ & 0.34 & 0.41 & $0.28,0.59$ & $<0.01$ \\
\hline
\end{tabular}

SES, socio-economic status.

*Odds ratios of obesity estimated for each sex (stratified analysis) taking account of the contrasts between races and interaction term. †Interaction term tested was statistically significant $(P<0.02)$.

$\ddagger$ The estimates were calculated for three SES factor levels: a lower level ( -2 standard deviations of the SES factor); middle level (0 standard deviations) and an upper level (+2 standard deviations).

Table 4 Effects of the socio-economic status (SES) factor on obesity according to race and sex among Brazilian adults from urban areas ( $n$ 80 702): 2008-2009 Brazilian Household Budget Survey

\begin{tabular}{|c|c|c|c|c|c|c|}
\hline & \multicolumn{3}{|c|}{ Men ( $n$ 38391) } & \multicolumn{3}{|c|}{ Women (n 42311) } \\
\hline & $\mathrm{OR}^{*}$ & $95 \% \mathrm{Cl}$ & $P$ & $\mathrm{OR}^{*}$ & $95 \% \mathrm{Cl}$ & $P$ \\
\hline \multicolumn{7}{|c|}{ Increase per $1 \mathrm{SD}$ of the SES factor } \\
\hline White & $1 \cdot 12$ & $1.05,1.20$ & $<0.01$ & 0.81 & $0.76,0.86$ & $<0.01$ \\
\hline Black & 1.37 & $1 \cdot 16,1 \cdot 62$ & $<0.01$ & $1 \cdot 17$ & $1 \cdot 02,1 \cdot 34$ & 0.03 \\
\hline Brown & 1.26 & $1 \cdot 18,1 \cdot 36$ & $<0.01$ & 0.87 & $0.81,0.92$ & $<0.01$ \\
\hline
\end{tabular}

*Odds ratios of obesity were estimated for each sex (stratified analysis) and race by taking account of race + age $(y e a r s)+$ region + SES factor (individual factor scores) + interaction term race $\times$ SES factor. 
partially explained by their life-course low socio-economic position, while no association was verified among men. Robert and Reither ${ }^{(38)}$, using multilevel analysis, observed that higher BMI among Black American women persisted even after considering individual SES and community socio-economic disadvantages; no association was observed for men. In an American population-based study, Jackson et al. ${ }^{(10)}$ verified that Blacks, particularly women, experienced higher increases in BMI from 1997 to 2008 than Whites, for whom the obesity trends and racial disparities were more noticeable among individuals with higher education levels. Baltrus et al. ${ }^{(39)}$ observed that weight gain over 34 years in adulthood was greater in Blacks than in Whites among women only. However, the association of race with weight gain largely resulted from the use of a cumulative socio-economic position score. Moreover, previous studies have revealed racial disparities in obesity since early childhood and adolescence, with Black children having higher BMI compared with Whites ${ }^{(35,40,41)}$; these differences cannot be explained by socio-economic variations between the examined groups ${ }^{(6,42)}$.

Despite studies on American males showing quite different results, with Blacks and those with lower SES having a higher prevalence of obesity ${ }^{(4,43)}$, in our study we observed that White men and those with greater SES level had the highest odds of obesity. Further, among men, American national data revealed limited differences in the prevalence of obesity from 1999 to 2010 according to race, whereas the prevalence among non-Hispanic Black women was 20 percentage points higher than that among non-Hispanic White women ${ }^{(9)}$. Gigante et al. ${ }^{(16)}$ identified no difference in obesity by race in Brazilian men, while Black or mixed women had a greater prevalence of obesity and overweight status compared with Whites.

In the present study, the associations of obesity and race were statistically significant for men only at lower SES levels, in which Black and Brown men had lower odds of obesity compared with White men. In addition, the odds of obesity among men increased with an increase in the SES factor among all racial categories, especially for Black men. These results indicate that the effect of increasing SES factor level on obesity was more evident among Black people, both for men and women.

In summary, the present population-based study suggests that racial disparities in obesity are SES level- and sex-dependent. The role of race in obesity was markedly evident in women, for whom the current Brazilian strategies exclusively targeting reductions in SES disparities probably will not be effective for decreasing racial disparities in obesity. The complex patterns in the association between race and obesity and the complexity of variables involved in the pathways of this relationship suggest the need for further studies including other variables allowing improved measurements of latent constructs, such as SES and discrimination, and the need for analysing the interactions and mediations among these constructs. Such an approach would be more appropriate for establishing guidelines for the prevention of obesity in countries with highly heterogeneous populations, such as in Brazil.

\section{Acknowledgements}

Financial support: This research received no specific grant from any funding agency in the public, commercial or not-for-profit sectors. M.C.A. received a postdoctoral fellowship from the Brazilian Federal Agency for the Improvement of Higher Education (Coordenação de Aperfeiçoamento de Pessoal de Nível Superior - CAPES). CAPES had no role in the design, analysis or writing of this article. Conflict of interest: None of the authors has conflicts of interest. Authorship: M.C.A., R.S. and V.T.B. contributed to the design of the study, analysis and interpretation of the data and the drafting of the manuscript; E.M.Y. contributed to the interpretation of the data and the drafting of the manuscript. All authors read and approved the final manuscript. Ethics of buman subject participation: This study is a secondary analysis of 2008-2009 HBS data available for public online access from the Brazilian Institute of Geography and Statistics, which respects the confidentiality and ethical aspects of individuals under Brazilian Government law (number 73177 of 20 November 1973).

\section{References}

1. Kleinert S \& Horton R (2015) Rethinking and reframing obesity. Lancet 385, 2326-2328.

2. World Health Organization (2013) Global Action Plan for the Prevention and Control of Noncommunicable Diseases 2013-2020. Geneva: WHO; available at http://www.who. int/nmh/publications/ncd-action-plan/en/

3. NCD Risk Factor Collaboration (2016) Trends in adult bodymass index in 200 countries from 1975 to 2014: a pooled analysis of 1698 population-based measurement studies with $19 \cdot 2$ million participants. Lancet 387, 1377-1396.

4. Wong RJ, Chou C \& Ahmed A (2014) Long term trends and racial/ethnic disparities in the prevalence of obesity. J Community Health 39, 1150-1160.

5. Drewnowski A \& Specter SE (2004) Poverty and obesity: the role of energy density and energy costs. Am J Clin Nutr 79 , 6-16.

6. Wang Y, Monteiro C \& Popkin BM (2002) Trends of obesity and underweight in older children and adolescents in the United States, Brazil, China, and Russia. Am J Clin Nutr $\mathbf{7 5}$, 971-977.

7. Conde WL \& Monteiro CA (2014) Nutrition transition and double burden of undernutrition and excess of weight in Brazil. Am J Clin Nutr 100, issue 6, 1617S-1622S.

8. Monteiro CA, Moura EC, Conde WL et al. (2004) Socioeconomic status and obesity in adult populations of developing countries: a review. Bull World Health Organ 82, 940-946.

9. May AL, Freedman D, Sherry B et al. (2013) Obesity United States, 1999-2010. MMWR Suppl 62, 120-128.

10. Jackson CL, Szklo M, Yeh HC et al. (2013) Black-white disparities in overweight and obesity trends by educational attainment in the United States, 1997-2008. J Obes 2013, 140743. 
11. Grabner M (2012) BMI trends, socioeconomic status, and the choice of dataset. Obes Facts 5, 112-126.

12. Chor D, Faerstein E, Kaplan GA et al. (2004) Association of weight change with ethnicity and life course socioeconomic position among Brazilian civil servants. Int J Epidemiol 33, 100-106.

13. Instituto Brasileiro de Geografia e Estatística (2010) Pesquisa de Orçamentos Familiares 2008-2009 - Despesas, Rendimentos e Condições de Vida. Rio de Janeiro: IBGE.

14. World Health Organization (1995) Physical Status: The Use and Interpretation of Anthropometry. Report of a WHO Expert Committee. WHO Technical Report Series no. 854. Geneva: WHO; available at http://www.who.int/ childgrowth/publications/physical_status/en/index.html

15. Instituto Brasileiro de Geografia e Estatística (2010) Pesquisa de Orcamentos Familiares 2008-2009: Antropometria e Estado Nutricional de Crianças, Adolescentes e Adultos no Brasil. Rio de Janeiro: IBGE.

16. Gigante DP, Minten GC, Horta BL et al. (2008) Nutritional evaluation follow-up of the 1982 birth cohort, Pelotas, Southern Brazil. Rev Saude Publica 42, 60-69.

17. Sobal J \& Stunkard AJ (1989) Socioeconomic status and obesity: a review of the literature. Psychol Bull 105, 260-275.

18. Dinsa GD, Goryakin Y, Fumagalli E et al. (2012) Obesity and socioeconomic status in developing countries: a systematic review. Obes Rev 13, 1067-1079.

19. Schmidt MI, Duncan BB, Silva GA et al. (2011) Chronic non-communicable diseases in Brazil: burden and current challenges. Lancet 377, 1949-1961.

20. Paradies Y (2006) A systematic review of empirical research on self-reported racism and health. Int J Epidemiol 35, 888-901.

21. Williams DR, Neighbors HW \& Jackson JS (2003) Racial/ ethnic discrimination and health: findings from community studies. Am J Public Health 93, 200-208.

22. Gee GC, Ro A, Gavin A et al. (2008) Disentangling the effects of racial and weight discrimination on body mass index and obesity among Asian Americans. Am J Public Health 98, 493-500.

23. Rosmond R (2005) Role of stress in the pathogenesis of the metabolic syndrome. Psychoneuroendocrinology 30, 1-10.

24. Dallman MF, la Fleur SE, Pecoraro NC et al. (2004) Minireview: glucocorticoids - food intake, abdominal obesity, and wealthy nations in 2004. Endocrinology 145, 2633-2638.

25. Björntorp P (2001) Do stress reactions cause abdominal obesity and comorbidities? Obes Rev 2, 73-86.

26. Rosmond R, Dallman M \& Björntorp P (1998) Stress-related cortisol secretion in men: relationships with abdominal obesity and endocrine, metabolic and hemodynamic abnormalities. J Clin Endocrinol Metab 83, 1853-1859.

27. Womble LG, Williamson DA, Martin NL et al. (2001) Psychosocial variables associated with binge eating in obese males and females. Int J Eat Disord 30, 217-221.
28. Yanovski S (1993) Binge eating disorder: current knowledge and future directions. Obes Res 4, 306-324.

29. Chambers EC, Tull ES, Fraser HS et al. (2004) The relationship of internalized racism to body fat distribution and insulin resistance among African adolescent youth. $J$ Natl Med Assoc 96, 1594-1598.

30. Tull E, Wickramasuriya T, Taylor J et al. (1999) Relationship of internalized racism to abdominal obesity and blood pressure in Afro-Caribbean women. I Natl Med Assoc 9, 447-452.

31. Butler C, Tull ES, Chambers EC et al. (2002) Internalized racism, body fat distribution and abnormal fasting glucose among African-Caribbean women in Dominica, West Indies. J Natl Med Assoc 94, 143-148.

32. Millstein RA, Carlson SA, Fulton JE et al. (2008) Relationships between body size satisfaction and weight control practices among US adults. Medscape J Med 10, 119.

33. Kumanyika SK (2008) Environmental influences on childhood obesity: ethnic and cultural influences in context. Physiol Behav 94, 61-70.

34. Powell AD \& Kahn AS (1995) Racial differences in women's desires to be thin. Int J Eat Disord 17, 191-195.

35. Kwate NO, Yau CY, Loh JM et al. (2009) Inequality in obesigenic environments: fast food density in New York City. Health Place 15, 364-373.

36. Lim S \& Harris TG (2015) Neighborhood contributions to racial and ethnic disparities in obesity among New York City adults. Am J Public Health 105, 159-165.

37. Centers for Disease Control and Prevention (2010) Racial and ethnic differences in breastfeeding initiation and duration, by state - National Immunization Survey, United States, 2004-2008. MMWR Morb Mortal Wkly Rep 59, 27-34.

38. Robert SA \& Reither EN (2004) A multilevel analysis of race, community disadvantage, and body mass index among adults in the US. Soc Sci Med 59, 2421-2434.

39. Baltrus PT, Lynch JW, Everson-Rose S et al. (2005) Race/ ethnicity, life-course socioeconomic position, and body weight trajectories over 34 years: the Alameda county study. Am J Public Health 95, 1595-1601.

40. Kenney MK, Wang J \& Iannotti R (2014) Residency and racial/ethnic differences in weight status and lifestyle behaviors among US youth. J Rural Health 30, 89-100.

41. Weden MM, Brownell P \& Rendall MS (2012) Prenatal, perinatal, early life, and sociodemographic factors underlying racial differences in the likelihood of high body mass index in early childhood. Am J Public Health 102, 2057-2067.

42. Karlsen S, Morris S, Kinra S et al. (2014) Ethnic variations in overweight and obesity among children over time: findings from analyses of the Health Surveys for England 1998-2009. Pediatr Obes 9, 186-196.

43. Zhang H \& Rodriguez-Monguio R (2012) Racial disparities in the risk of developing obesity-related diseases: a cross-sectional study. Ethn Dis 22, 308-316. 